\title{
Energy flow modeling and optimization trends in food supply chain: a mini review
}

\author{
Amin Nikkhah ${ }^{a, b, *}$, Sam Van Haute ${ }^{a, b, *}$ \\ ${ }^{a}$ Department of Environmental Technology, Food Technology and Molecular Biotechnology, Ghent \\ University Global Campus, Incheon, South Korea \\ ${ }^{\mathrm{b}}$ Faculty of Bioscience Engineering, Ghent University, Coupure Links 653, 9000 Ghent, Belgium \\ E-mail address: Amin.Nikkhah@ugent.be \\ E-mail address: sam.vanhaute@ghent.ac.kr
}

\begin{abstract}
Energy auditing, modeling and optimization are the important tools which can be considered toward achieving a sustainable food supply chain (FSC). In this regard, energy modeling and optimization have become a hot topic in the food sector and thus, several mathematical and computational intelligent-based systems have been applied to model and optimize the energy flows of FSC. This study briefly reviewed the widely used mathematical (multiple linear regressions, data envelopment analysis) and computational intelligent-based (artificial neural networks, adaptive neuro fuzzy inference systems, genetic algorithm) approaches for modeling and optimization of the energy flow in FSC. Based on the literature review it can be inferred that computational intelligent based approaches could better model and optimize the energy flows than mathematical approaches and the performance of computational intelligent-based systems showed that this approach can be generally applicable for modeling and optimizing energy flows of FSC.
\end{abstract}

Keywords: Energy consumption, Food production, Intelligent system, Mathematical modeling 


\section{Energy auditing}

Food supply chain (FSC) refers to a network of food-based business enterprises in which food products move from farm to fork, involving off-farm and on-farm operations, processing, packaging, food service, and consumption activities (Zhang and Li, 2012).

Energy auditing, modeling and optimization are the important methodologies which can be considered toward moving to a sustainable FSC. Energy auditing can be considered as the foremost step to investigate the energy consumption of production systems and to specify the measures which may be taken toward moving to a more energy-efficient production system (Soltanali et al., 2017). In fact, energy use efficiency has a strategic advantage for producers, and is not just a marginal issue (Marchi and Zanoni, 2017).

The energy coefficients of inputs refer to the total consumed energy in the whole cycle of the production (from primary production to the end of process) (Mousavi-Avval et al., 2011; Hosseinzadeh-Bandbafha et al., 2018). For instance, the energy equivalent of diesel fuel is 56.3 $\mathrm{MJkg}^{-1}$ (Persiani et al., 2019) and biocide is $120 \mathrm{MJkg}^{-1}$ (Yadav et al., 2018). The energy output refers to the gross energy content measured by laboratory bomb calorimeter tests (MousaviAvval et al., 2011). As an example, the energy content of wheat is $56.3 \mathrm{MJkg}^{-1}$ (Kazemi et al., 2015) and rice is $14.5 \mathrm{MJkg}^{-1}$ (Yuan et al., 2019).

The functional unit (FU) in energy analysis studies gives the reference by which various food supply chains can be compared. The land-based and mass-based functional units are prevalent in assessing the energy flows of food supply chains (Khojastehpour et al., 2015; Gökdoğan et al., 2019; Talukder and Hipel, 2019). The main energy indices which have been applied in FSC are energy use efficiency, specific energy, energy productivity, and net energy (MohammadiBarsari, et al., 2016). 


\section{The importance of energy modeling and optimization of FSC}

Energy auditing of FSC is one of the important steps toward sustainability (Esmailpour-Troujeni et al., 2018). It determines the energy hotspots of the production system and it may help to save considerable amounts of energy, money, and also mitigation of environmental impacts. Farmers and manufactures should be aware of the energy usage during the production of their products due to the increasing regulations and legal requirements which require reduction of energy usage and environmental impacts (Meyers et al., 2016).

Agriculture is an energy-intensive sector (Hassapoyannes and Blandford, 2019; Firouzi et al., 2018; Gökdoğan et al., 2019), and the food processing industry is one of the highest consumers of energy in the manufacturing sector (Compton et al, 2018). Overall, the food sector consumes globally about $200 \mathrm{EJ}$ per year (Bakalis et al., 2019). It is a necessity that measures are taken to reduce the energy consumption in FSC.

Modeling and optimization techniques are the strong tools to contribute toward management of energy consumption in FSC. A few studies have been focused on energy modeling and optimization of food processing, but so far, most of the studies on energy modeling and optimization of FSC have been focused on modeling and optimizing the agricultural phase of production systems. The lack of studies on food processing and packaging is mainly due to unavailability or inaccessibility of data. There are still a few studies on modeling and optimization of energy flows of different phases of food supply chain which are discussed in the following sections. 


\section{Modeling}

Several mathematical modeling techniques have been applied to model the energy patterns of FSC. The following sections discuss the commonly used mathematical and computational intelligent-based modeling techniques.

\section{Mathematical modeling}

Multiple linear regression is one of the widely used mathematical models for energy use modeling of FSC. Cobb-Douglas (CD) has been used in several studies for FSC energy modeling like chicken (Heidari et al., 2011), melon (Sharifi, 2018), and pomegranate (Esmailpour-Troujeni et al., 2018). The following equation expresses the general form of the CS model (Taheri-Rad et al., 2017):

$L y_{i}=a_{0}+\alpha_{1} l \eta x_{1}+\alpha_{2} l \eta x_{2}+\alpha_{3} l>x_{3}+\cdots+\alpha_{\mathrm{I}} l \eta x_{n}+e_{\mathrm{i}}$

where $y_{i}$ is the output energy of farm/processing/packaging $i_{t h}, x_{i}$ is the consumed inputs in production, and $\alpha_{1}, \alpha_{2}, \ldots, \alpha_{n}$ are the regression coefficients of energy inputs, $a_{0}$ is the constant coefficient, and $e_{i}$ is the error coefficient.

In a study conducted by Rajaeifar et al. (2014), the CD model was employed for energy flow modelling within olive oil supply chain. They developed a $\mathrm{CD}$ model with $\mathrm{R}^{2}$ of 0.92 . Bartzasa and Komnitsas, (2018) employed the CD model for energy modeling of a pistachio production system in Greece. The results showed that among energy inputs, fertilizers and machinery had statistically significant positive effects on the yield of pistachio. As was mentioned, CD model has been widely applied for energy flows modeling of FSC; however, recent studies indicate that computational intelligent-based models could better model the energy flows of FSC than those of multiple regressions models (Safa and Samarasinghe, 2011; Bolandnazar et al., 2019). The following section explains commonly used computational intelligent-based models from the 
point of view of energy flows modeling of FSC.

\section{Artificial intelligent-based modeling}

Artificial Neural Networks (ANN) and Adaptive Neuro Fuzzy Inference System (ANFIS) are the two commonly used AI systems in energy modeling of FSC. So far, Multilayer Perceptron (MLP) and Radial Basis Function (RBF) have been applied to develop ANNs to model energy flows of FSC. MLP is the most common type of feed forward neural networks (Khoshroo et al., 2018). Fig. 1 demonstrates the general structure of a typical MLP model. An MLP neural network has at least three layers and its goal is to develop an optimal model through determination of the best weights between nodes of the input variables and hidden layers $\left(\mathrm{W}_{1}\right)$ as well as between nodes of the hidden and output layer $\left(\mathrm{W}_{2}\right)$ (Bolandnazar et al., 2019). Some studies showed the high accuracy of this model in different FSC such as wheat (Safa and Samarasinghe, 2011), basil (Rostami et al., 2017), and grape (Mardani and Taghavifar, 2016).

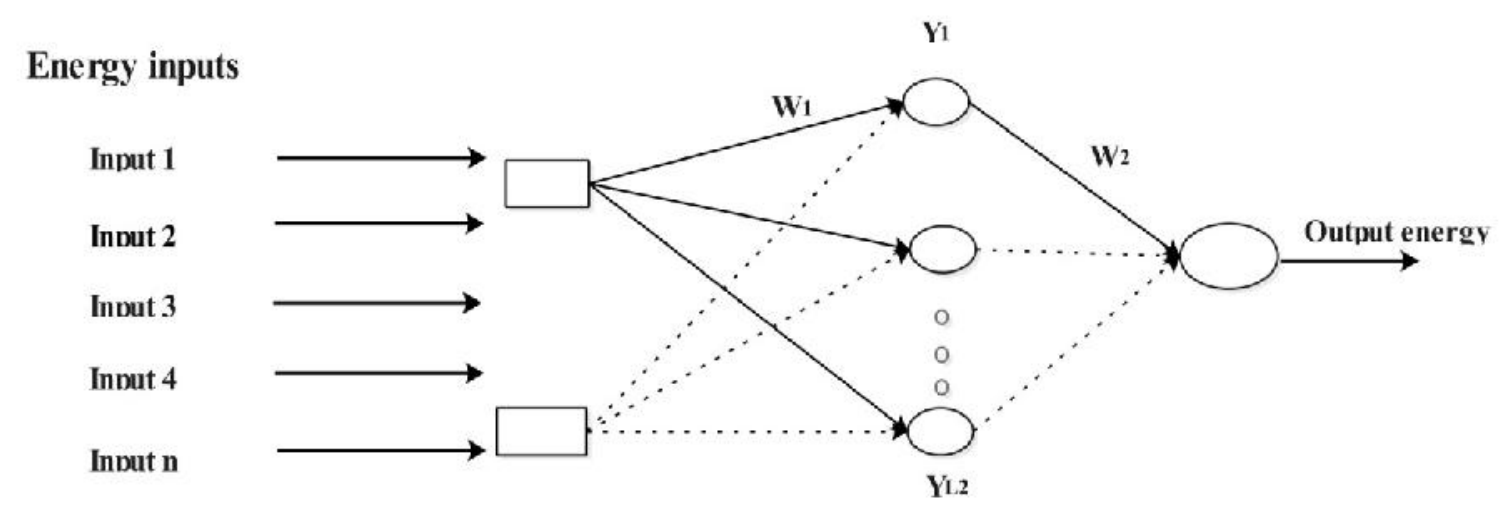

Fig. 1. Configuration of MLP artificial neural network for energy flow modeling of FSC (Nikkhah et al., 2019)

Radial Basis Function (RBF) is one type of ANNs that applies radial basis functions as its activation functions. It consists of the linear combination of radial basis functions and a RBF 
model has a single hidden layer (Sadri and Burn, 2012) (Fig. 2). Taki et al. (2018) and Bolandnazar et al. (2019) modeled the energy flow of wheat and potato production systems, respectively, using MLP and RBF neural networks. Both studies highlighted that RBF neural network based models were more accurate than MLP.

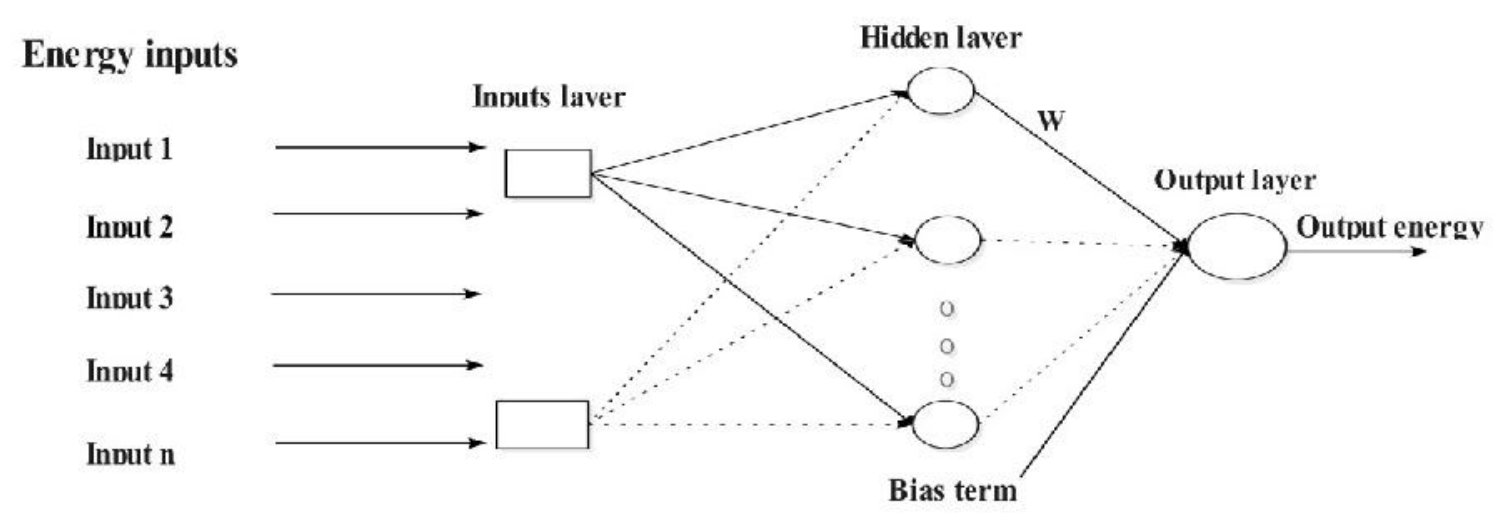

Fig. 2. Configuration of RBF artificial neural network to energy flow modeling of FSC (KosariMoghaddam et al., 2019)

ANFIS is a combination of ANN and fuzzy-logic model which is capable to model uncertain and imprecise data (Ekici and Aksoy, 2011). It is able to simulate the mapping relation between the input variables and output by using hybrid learning in order to specify the optimal distribution of the membership functions (Iphar et al., 2008). Fig. 3 displays the general structure of ANFIS for energy flow modeling of FSC.

In a study, ANFIS and ANN were employed to prognosticate the energy output of an egg production system based on the energy inputs data. The results revealed that the developed ANFIS modeled the energy flow of the production system more accurately than the ANN model (Sefeedpari et al., 2016). The results of the study on tomato production also indicated that ANFIS could more effectively model the energy flow (Khoshnevisan et al., 2017). Owing to the high degree of accuracy, ANFIS has been recently applied to model the energy flows of some 
FSC like dairy product (Hosseinzadeh-bandbafha et al., 2016), rice (Nabavi-Pelesaraei et al., 2019), and sugarcane (Kaab et al., 2019).

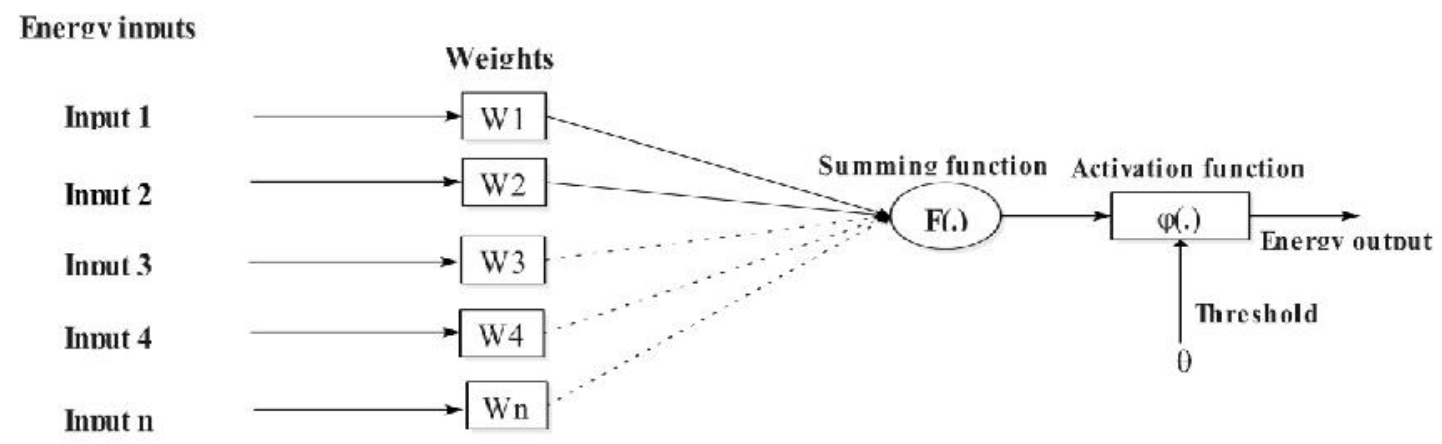

Fig. 3. Configuration of ANFIS for energy flow modeling of FSC (Sefeedpari et al., 2016)

\section{Optimization}

Data Envelopment Analysis (DEA) and Genetic Algorithm (GA) are considered as the two widely applied optimization techniques in FSC. The following paragraphs explain the application of these techniques in the point of optimization of energy flows of FSC.

\section{Data Envelopment Analysis}

DEA is a linear programming approach for evaluating the efficiency of Decision-Making Units (DMUs). DEA gives the relative efficiency of the DMUs which consume different amounts of inputs for producing the same output (Omid et al., 2012). Cooper and Rhodes (CCR) and Banker-Charnes-Cooper (BCC) are the two approaches for measuring returns to scale in the DEA analysis (Othman et al., 2016). The general structure of a DEA approach in energy optimization of FSC is shown in Fig. 4. DEA have been used in FSC in order to determine the efficient and inefficient units in terms of energy management. 


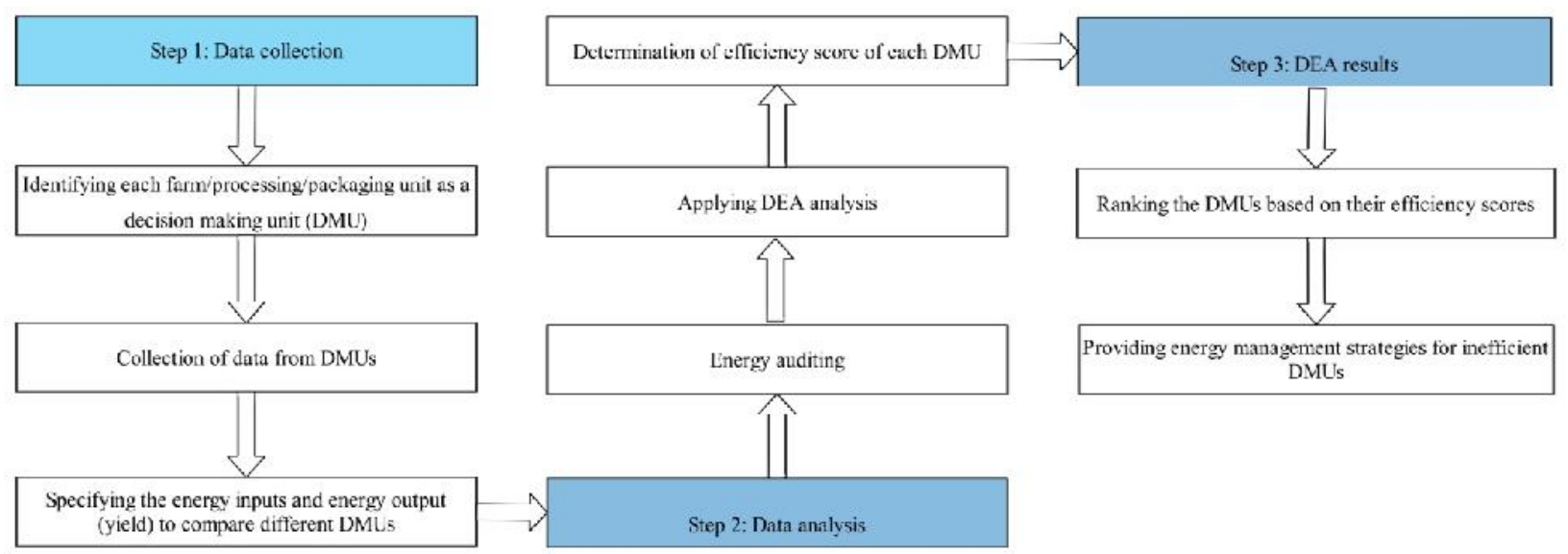

Fig. 4. The general structure of DEA for energy optimization of FSC

Masuda et al., (2018) studied the energy efficiency of olive production in Japan. The energy efficiency scores varied from 0.732 for farms of one hectare to $<2$ hectares, to 0.988 for farms larger than 15 hectares. They claimed that there is a significant variation in efficiency scores, demonstrating that there is an opportunity for restructuring the production process in order to improve the energy use efficiency. A similar study on olive oil production in Greece indicated the significant variations of efficiency scores of the DMUs, which might be an opportunity to optimize the process in terms of energy management (Niavis et al., 2018).

\section{Genetic Algorithm}

GA, an optimization technique based on the Darwinian evolution model (Fig. 5), finds the value of parameters based on the basic principle that only the best solution survives and is also capable of creating qualified offspring (Gomes et al., 2015; Sampebatu, L., 2015). Usually, the goal of the optimization in FSC is to determine the appropriate level of the energy inputs to reach the highest energy output. All of the mentioned models like CD, ANN and ANFIS can be applied as the fitness/cost functions for GA. 
Fig. 5 demonstrates the general structure of GA for optimization of energy in FSC. A GA begins with a random population of chromosomes (solutions) (Jafari and Rohani, 2016). The next step is to evaluate the population of chromosomes through the fitness function, which returns the best solutions for the next generation of population (Melo et al., 2017). The lower and upper bounds to be used for energy optimization in FSC may be considered as the minimum and maximum values (Nabavi-Pelesaraei et al., 2017), or it can be selected based on expert recommendation (Shamshirband et al., 2016; Mousavi-Avval et al. 2016).

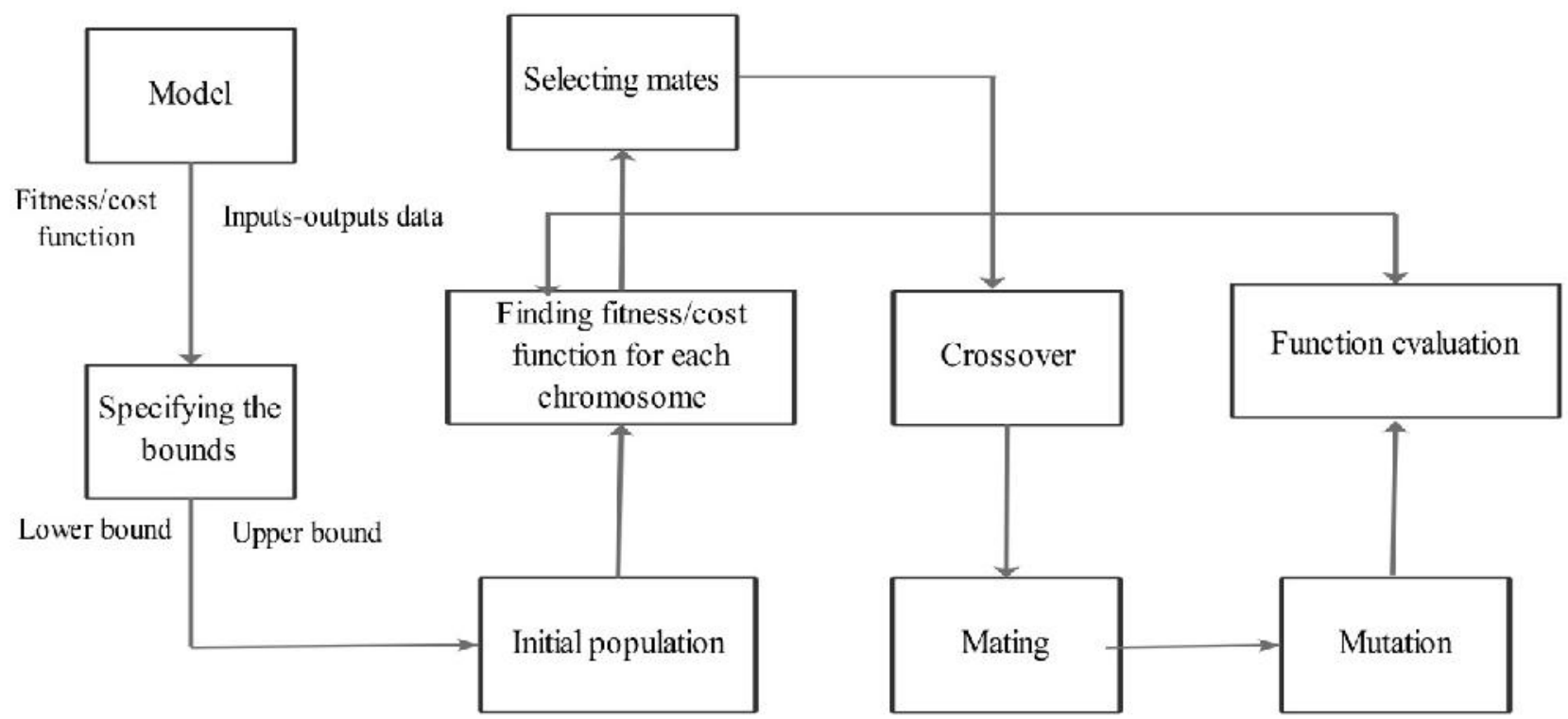

Fig. 5. The general structure of GA (Haupt and Haupt, 2004; Soltanali et al., 2017)

GA could better optimize the energy flows of FSC than DEA models in FSC (NabaviPelesaraei et al 2016,2017). More specifically, one study indicated that the energy savings potential by employing GA and DEA for sugarcane production were $21 \%$ and $8 \%$, respectively (Kaab et al., 2019). Fig. 6 summaries the models and optimization techniques which have been applied in FSC. As mentioned, ANFIS has the highest accuracy for FSC energy modeling and GA also can be considered as a strong tool for optimization of energy flows in FSC. As a result, 
the hybrid application of ANFIS+ GA may be considered as a powerful tool to model and optimize the energy in FSC in the future studies.

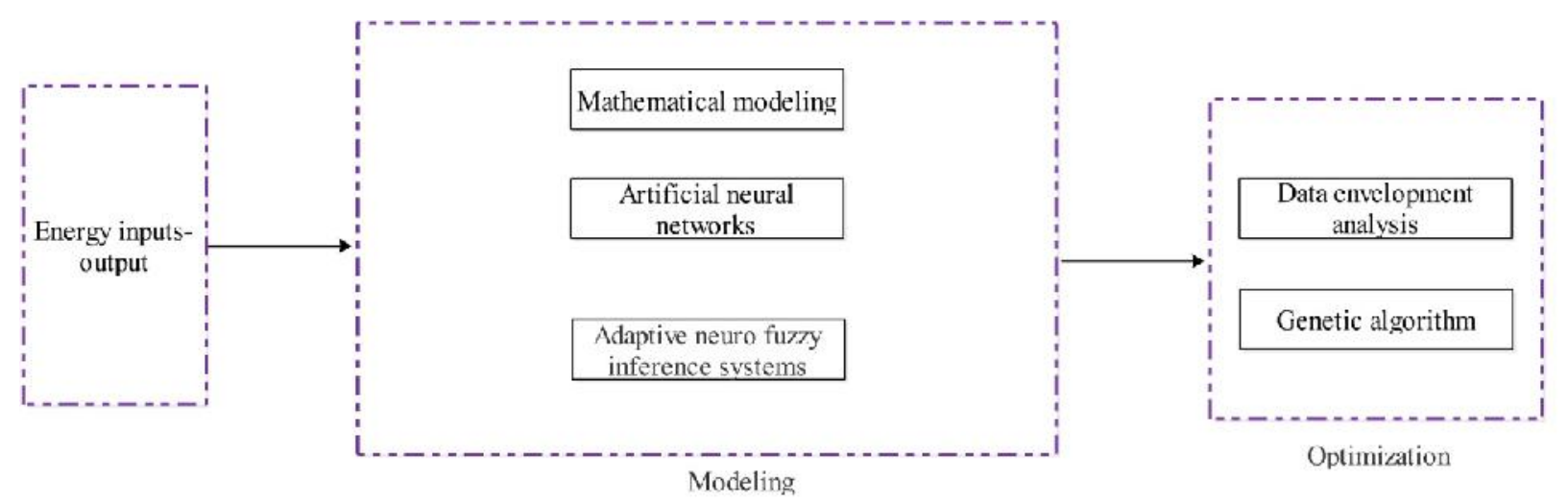

Fig. 6. Modeling and optimization techniques in FSC

\section{Conclusions}

Energy flows modeling and optimization of food supply chain is a complex task. In recent years, several tools have been applied to optimize and model the energy flow of FSC, especially in the agricultural phase of the production system. The results reveal that the computational intelligent-based tools are more accurate and powerful than mathematical modeling. More specifically, ANFIS and GA are the best ones for modeling and optimizing the energy flow of a food supply chain, respectively. Until now, as was mentioned, several models have been employed for energy flow modeling of FSC; however, only DEA and GA have been used for optimization purposes. Therefore, it is recommended that some new optimization techniques like Particle Swarm Optimization are applied for the energy optimization of FSC and compared with the previously used optimization tools.

\section{Acknowledgment}

The research leading to these results has received funding from Ghent University Global, is gratefully acknowledged. 


\section{References}

Bakalis S, Fryer PJ, Lopez-Quiroga E: Mapping energy consumption in food manufacturing. Trends in Food Science \& Technology 2019, 86: 270-280.

Bartzas G, Komnitsas K: Energy flow analysis in agriculture; the case of irrigated pistachio production in Greece. Sustainable Energy Technologies and Assessments 2018, 28:7380.

Bolandnazar E, Rohani A, Taki M: Energy consumption forecasting in agriculture by artificial intelligence and mathematical models. Energy Sources, Part A: Recovery, Utilization, and Environmental Effects 2019, 1-15. The authors compared mathematical and artificial intelligence approaches to model the energy flows of a food production system.

Compton M, Willis S, Rezai, B, Humes $\mathrm{K}$ : Food processing industry energy and water consumption in the Pacific northwest. Innovative food science \& emerging technologies 2018, 47:371-383.

Ekici BB, Aksoy UT: Prediction of building energy needs in early stage of design by using ANFIS. Expert Systems with Applications 2011, 38(5):5352-5358.

Esmailpour-Troujeni ME, Khojastehpour M, Vahedi A, Emadi B: Sensitivity analysis of energy inputs and economic evaluation of pomegranate production in Iran. Information processing in agriculture 2018, 5(1):114-123.

Firouzi S, Nikkhah A, Aminpanah H: Resource use efficiency of rice production upon single cropping and ratooning agro-systems in terms of bioethanol feedstock production. Energy 2018, 150:694-701. The authors studied the energy use efficiency of a food production system in order to generate biofuel.

Gökdoğan O, Erdoğan O, Ertan E, Çobanoğlu F: Evaluation of Energy and Economic Analysis of Chestnut (Castanea Sativa Mill.) Fruit Production in Turkey. ErwerbsObstbau 2019, 1-6. 
Gökdoğan O, Erdoğan O, Ertan E, Çobanoğlu F: Evaluation of Energy and Economic Analysis of Chestnut (Castanea Sativa Mill.) Fruit Production in Turkey. ErwerbsObstbau, 2019,1-6.

Gomes RC, Vitorino MA, Corrêa MB, Wang R, Fernandes DA: Photovoltaic parameter extraction using Shuffled Complex Evolution. In 2015 IEEE 13th Brazilian Power Electronics Conference and 1st Southern Power Electronics Conference (COBEP/SPEC), IEEE 2015, 1-6.

Hassapoyannes K, Blandford D: Agriculture and Climate Change: National and International Policy Response. Global Challenges For Future Food And Agricultural Policies 2019, 1, p.217.

Heidari MD, Omid M, Akram A: Energy efficiency and econometric analysis of broiler production farms. Energy 2011, 36(11):6536-6541.

Hosseinzadeh-Bandbafha H, Nabavi-Pelesaraei A. Khanali M, Ghahderijani M, Chau KW: Application of data envelopment analysis approach for optimization of energy use and reduction of greenhouse gas emission in peanut production of Iran. Journal of cleaner production 2018, 172:1327-1335.

Hosseinzadeh-bandbafha H, Safarzadeh D, Ahmadi E, Nabavi-Pelesaraei A: Modelling Output Energy and Greenhouse Gas Emissions of Dairy Farms Using Adaptive Neural Fuzzy Inference System. Agricultural Communications 2016, 4(2):14-23.

Iphar M, Yavuz M, Ak H: Prediction of ground vibrations resulting from the blasting operations in an open-pit mine by adaptive neuro-fuzzy inference system. Environmental Geology 2008, 56(1):97-107.

Jafari M, Rohani, A: Optimization of perforated composite plates under tensile stress using genetic algorithm. Journal of Composite Materials 2016, 50(20):2773-2781.

Kaab A, Sharifi M, Mobli H, Nabavi-Pelesaraei A, Chau KW: Combined life cycle assessment and artificial intelligence for prediction of output energy and environmental impacts of sugarcane production. Science of the Total Environment 2019, 664:1005-1019. 
Kaab A, Sharifi M, Mobli H. Nabavi-Pelesaraei A, Chau KW: Use of optimization techniques for energy use efficiency and environmental life cycle assessment modification in sugarcane production. Energy 2019, 181 (15):1298-1320

Kazemi H, Kamkar B, Lakzaei S, Badsar M, Shahbyki M: Energy flow analysis for rice production in different geographical regions of Iran. Energy 2015, 84:390-396.

Khojastehpour M, Nikkhah A, Hashemabadi D: A comparative study of energy use and greenhouse gas emissions of canola production. International Journal of Agricultural Management and Development, 2015, 5(1): 51-58.

Khoshnevisan B, Rafiee S, Iqbal J, Shamshirband S, Omid M, Badrul AN, Abdul WA: A Comparative study between artificial neural networks and adaptive neuro-fuzzy inference systems for modeling energy consumption in greenhouse tomato production: a case study in Isfahan Province. J. Agr. Sci. Tech 2015, 17: 49-62.

Khoshroo A, Emrouznejad A, Ghaffarizadeh A, Kasraei M, Omid M: Sensitivity analysis of energy inputs in crop production using artificial neural networks. Journal of cleaner production 2018, 197:992-998.

Kosari-Moghaddam M, Rohani A, Kosari-Moghaddam L, Esmaeilpour-Troujeni M: Developing a radial basis function neural networks to predict the working days for tillage operation in crop production. International Journal of Agricultural Management and Development 2019,9(2):119-133, 2019.

Marchi B, Zanoni S: Supply chain management for improved energy efficiency: Review and opportunities. Energies 2017, 10(10):1618.

Mardani A, Taghavifar H: An overview on energy inputs and environmental emissions of grape production in West Azerbayjan of Iran. Renewable and Sustainable Energy Reviews 2016, 54:918-924.

Masuda K: Energy efficiency of intensive Rice production in Japan: an application of data envelopment analysis. Sustainability 2018, 10(1):120. The authors performed a DEA 
analysis based on the different sizes of farms. They concluded that the large farms are more energy efficient than the small farms.

Melo AB, Oliveira AM, de Souza DS, da Cunha, MJ: Optimization of Garbage Collection Using Genetic Algorithm. In 2017 IEEE 14th International Conference on Mobile Ad Hoc and Sensor Systems (MASS) 2017, (pp. 672-677). IEEE.

Meyers S, Schmitt B, Chester-Jones M, Sturm B: Energy efficiency, carbon emissions, and measures towards their improvement in the food and beverage sector for six European countries. Energy 2016, 104:266-283.

Mohammadi-Barsari A, Firouzi S, Aminpanah H: 2016. Energy-use pattern and carbon footprint of rain-fed watermelon production in Iran. Information Processing in Agriculture 2016,3(2):69-75.

Mousavi-Avval SH, Rafiee S, Jafari A, Mohammadi A: Energy flow modeling and sensitivity analysis of inputs for canola production in Iran. Journal of Cleaner Production 2011, 19(13):1464-1470. One of the first studies on energy flows modeling of food supply chain using the CD model.

Mousavi-Avval SH, Rafiee S, Jafari A, Mohammadi A: Optimization of energy consumption for soybean production using Data Envelopment Analysis (DEA) approach. Applied Energy 2011, 88(11):3765-3772. One of the first studies on energy flows modeling of food supply chain using the DEA model.

Mousavi-Avval SH, Rafiee S, Sharifi M, Hosseinpour S, Notarnicola B, Tassielli G, Renzulli PA: Application of multi-objective genetic algorithms for optimization of energy, economics and environmental life cycle assessment in oilseed production. Journal of Cleaner Production 2017, 140:804-815.

Nabavi-Pelesaraei A, Hosseinzadeh-Bandbafha H, Qasemi-Kordkheili P, Kouchaki-Penchah H. Riahi-Dorcheh F: Applying optimization techniques to improve of energy efficiency and GHG (greenhouse gas) emissions of wheat production. Energy 2016, 103:672678. 
Nabavi-Pelesaraei A, Rafiee S, Mohtasebi SS, Hosseinzadeh-Bandbafha H, Chau KW: Comprehensive model of energy, environmental impacts and economic in rice milling factories by coupling adaptive neuro-fuzzy inference system and life cycle assessment. Journal of cleaner production 2019, 217:742-756.

Nabavi-Pelesaraei A, Rafiee S, Mohtasebi SS, Hosseinzadeh-Bandbafha H, Chau KW: Energy consumption enhancement and environmental life cycle assessment in paddy production using optimization techniques. Journal of cleaner production 2017, 162:571-586.

Niavis S, Tamvakis N, Manos B, Vlontzos G: Assessing and explaining the efficiency of extensive olive oil farmers: The case of Pelion peninsula in Greece. Agriculture 2018, $8(2): 25$.

Nikkhah A, Rohani A, Rosentrater KA, El Haj Assad M, Ghnimi S: 2019. Integration of principal component analysis and artificial neural networks to more effectively predict agricultural energy flows. Environmental Progress \& Sustainable Energy 2019, 38(4):13130.

Omid M, Akram A, Pahlavan R: Application of Data Envelopment Analysis for Performance Assessment and Energy Efficiency Improvement Opportunities in Greenhouses Cucumber Production. J. Agr. Sci. Tech 2012, 14: 1465-1475.

Othman FM, Mohd-Zamil NA, Rasid SZA, Vakilbashi A, Ghasemi-Mokhber M: Data envelopment analysis: A tool of measuring efficiency in banking sector. International Journal of Economics and Financial Issues 2016, 6(3):911-916.

Persiani A, Diacono M, Monteforte A, Montemurro F:Agronomic performance, energy analysis, and carbon balance comparing different fertilization strategies in horticulture under Mediterranean conditions. Environmental Science and Pollution Research 2019, 1-11.

Rajaeifar MA, Akram A, Ghobadian B, Rafiee S, Heidari MD: Energy-economic life cycle assessment (LCA) and greenhouse gas emissions analysis of olive oil production in Iran. Energy 2014, 66:139-149. 
Rostami S, Choobin S, Samani BH, Esmaeili Z, Zareiforoush H: Analysis and modeling of yield, $\mathrm{CO} 2$ emissions, and energy for basil production in Iran using artificial neural networks. International Journal of Agricultural Management and Development (IJAMAD) 2017, 7:47-58.

Sadri S, Burn DH: Nonparametric methods for drought severity estimation at ungauged sites. Water Resources Research 2012, 48(12). https://doi.org/10.1029/2011WR011323

Safa M, Samarasinghe S: Determination and modelling of energy consumption in wheat production using neural networks:"A case study in Canterbury province, New Zealand. Energy 2011, 36(8):5140-5147.

Sampebatu L: Performance of artificial lighting using genetics algorithms. In 2015 3rd International Conference on Adaptive and Intelligent Agroindustry (ICAIA) 2015, (pp. 306-310). IEEE.

Sefeedpari P, Rafiee S, Akram A, Chau KW, Pishgar-Komleh SH: Prophesying egg production based on energy consumption using multi-layered adaptive neural fuzzy inference system approach. Computers and electronics in agriculture 2016, 131:10-19.

Shamshirband S, Khoshnevisan B, Yousefi M, Bolandnazar E, Anuar NB, Wahab AWA, Khan SUR: A multi-objective evolutionary algorithm for energy management of agricultural systems-a case study in Iran. Renewable and Sustainable Energy Reviews, 2015, 44:457-465.

Sharifi M:Energy inputs-Yield relationship and cost analysis of melon production in Khorasan Razavi province of Iran. Engineering in Agriculture, Environment and Food 2018, 11(3):109-113.

Soltanali H, Nikkhah A, Rohani A: Energy audit of Iranian kiwifruit production using intelligent systems. Energy 2017, 139:646-654. This is the first study that applied ANN as the fitness function for GA to optimize the energy flows of food supply chain. 
Taheri-Rad A, Khojastehpour M, Rohani A, Khoramdel S, Nikkhah A: Energy flow modeling and predicting the yield of Iranian paddy cultivars using artificial neural networks. Energy 2017, 135:405-412.

Taki M, Rohani A, Soheili-Fard F, Abdeshahi A: Assessment of energy consumption and modeling of output energy for wheat production by neural network (MLP and RBF) and Gaussian process regression (GPR) models. Journal of cleaner production 2018, 172:3028-3041.

Talukder B, Hipel KW: Energy efficiency of agricultural systems in the southwest coastal zone of Bangladesh. Ecological indicators 2019, 98:641-648.

Yadav GS, Das A, Lal R, Babu S, Meena RS, Saha P, Singh R, Datta M: Energy budget and carbon footprint in a no-till and mulch based rice-mustard cropping system. Journal of cleaner production 2018, 191:144-157.

Yuan S, Peng S, Wan D, Man J: Evaluation of the energy budget and energy use efficiency in wheat production under various crop management practices in China. Energy 2018, 160:184-191.

Zhang M, Li P: RFID application strategy in agri-food supply chain based on safety and benefit analysis. Physics Procedia 2012, 25:636-642. 